\title{
Nasal Encephalocoele: An Atypical Case
}

\author{
Anu Joy ${ }^{*}$, Kuldeep Moras" \\ "Resident, Department Of Otorhinolaryngology, Father Muller Medical College \\ ${ }^{* *}$ Professor, Department Of Otorhinolaryngology, Father Muller Medical College
}

\begin{abstract}
An encephalocoele is a congenital deformity in which the intracranial contents herniate through a defect in the skull. As the defect is more attributed to embryological development, it most commonly has a mean age of presentation ranging between 15.5 and 21 months.Nasal enchephalocoeles are herniation of cranial content through a bony defect in the anterior skull base into the nasal area. They are anterior encephalocoeles where meningeal herniation occurs through a midline defect in the floor of the anterior cranial fossa. The usual presentation of these cases is with a disfiguring swelling over the nose at the time of birth. When removal is indicated, there are multiple surgical approaches; including lateral rhinotomy, a transnasal approach and a coronal flap approach, involving a multi-disciplinary team of OtoRhinoLaryngology surgeons and Neuro surgeons. Here we report an atypical case of nasal encephalocoele, that presented later than usual age, with no external swelling or features of CSF leak and with a symptom of only unilateral nasal obstruction.The patient was treated successfully using a transnasal endoscopic approach which obviated the possible morbidity associated with other approaches.
\end{abstract}

Keywords: Nasal encephalocoele, nasal masses, meningoencephalocoele

\section{Introduction}

Encephaloceles are anomalous herniations of themeninges, or brainmatter and meninges, beyond theboundaries of the cranium; referred to as meningocele andeningoencephalocele respectively with a global incidence about 1 per 35,000 births. $^{1}$ The etiology is perhaps due to failure of the fonticulusfrontalis to closeproperly thus culminating in a herniation. ( Figure: 1 )

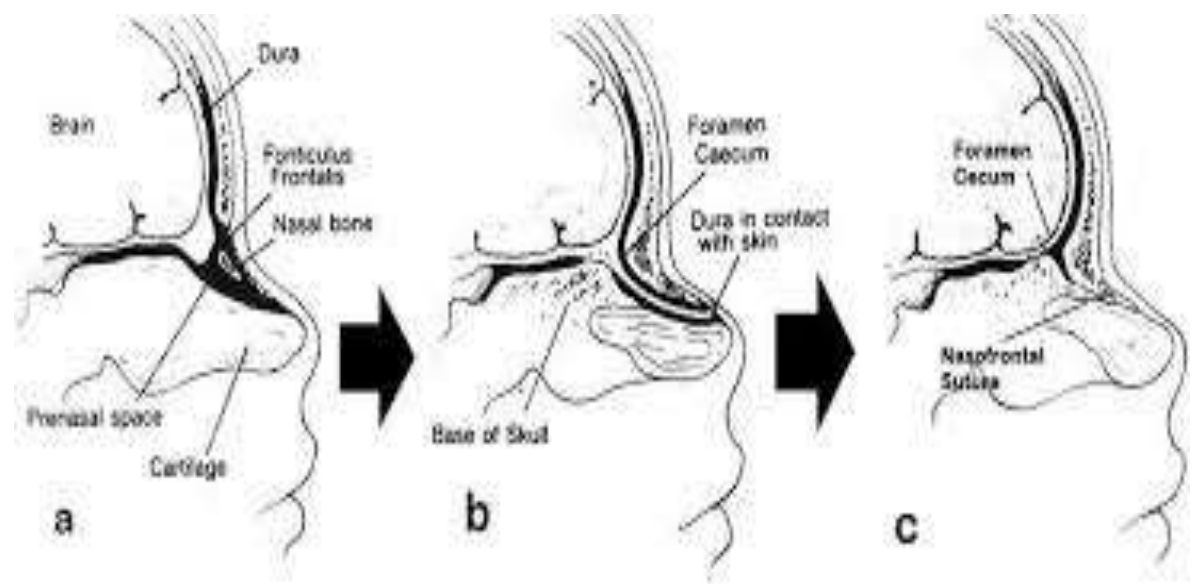

Figure 1

A. Fonticulus frontalis and Prenasal space; B. Clousure of Fonticulus frontalis, formation of Foramen caecum \& a projection of dural diverticulum contacts the tip of the nose; C.Retraction of Dural diverticulum and Obliteration of Prenasal space. (Source: Barkovich AJ, et al. Congenital nasal masses: CT and MR imaging features in 16 cases. Am J Neuroradiol 1991; 12:105-16)

Nasal enchephalocoeles are anterior encephalocoeles where meningeal herniation occurs through a midline defect in the floor of the anterior cranial fossa.They can be broadly divided into frontoethmoidal and basal encephaloceles. Both conditions are very rare, but frontoethmoidal encephaloceles show a relatively high incidence $(1: 5,000)$ in Southeast Asia. Patients with nasal encephaloceles typically presentwith a characteristic swelling on the nose and a soft compressible mass that transilluminates. The mass also enlarges on crying orvalsalva manoeuvre (Furstenberg sign Positive) and may be associated with CSF leak. Here we report an atypical case of nasal encephalocoele, that presented later than usual age, with no external swelling or features 
of CSF leak and with only a symptom of unilateral nasal obstruction, and successfully treated with endoscopic excision and repair of the cranial defect.

\section{Case Report}

A 28 year old female patient presented to the Otorhinolaryngology department of our hospital with complaints of right sided nasal obstruction since 1 year and right sided facial pain since 2 months. There was no history of watery nasal discharge, bleeding from nose, fever, headache, trauma to the nose or allergy. On examination, there was no external swelling, telecanthus or deformity of the nose (Figure :2) .

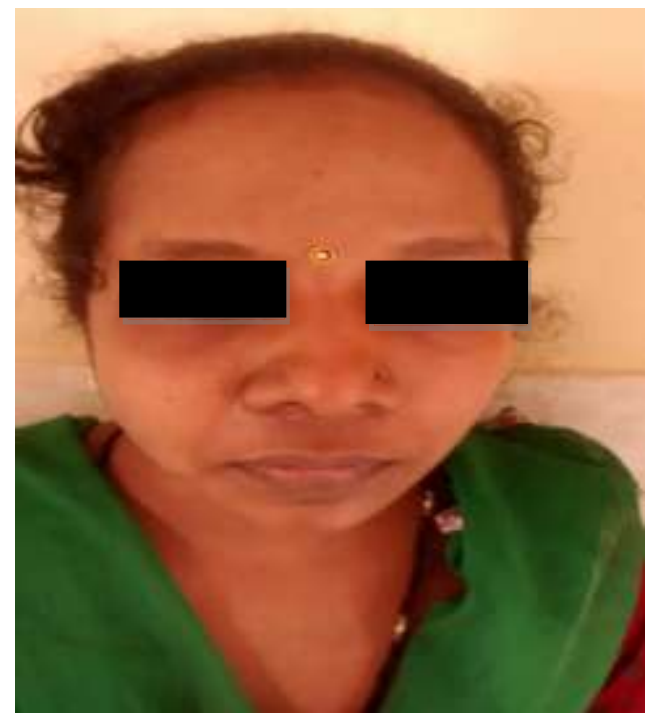

Figure : 2

Anterior rhinoscopy revealed polypoidal mass in the right nasal cavity. The consistency of the swelling was soft and appeared to be arising from the roof on probing. The mass could be seen almost filling the left choana in posterior rhinscopy. Her nasal cavities were adequate in size and there was no associated anosmia or discharge. The rest of the ENT examination was normal. There were no other associated congenital anomaly or neurological defect.

\section{Investigations:}

Computerised tomography showed a bony defect in the posterior fovea and a mass in the right nasal cavity, however the content of the mass could not be clearly delineated.(Figure. 3.)

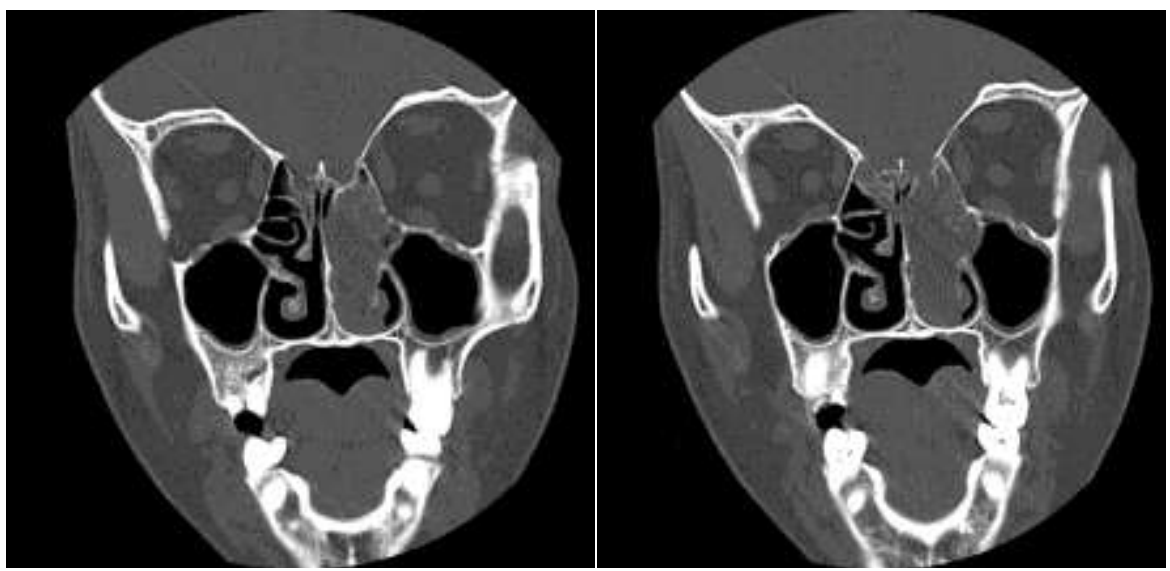

Figure 3.

Treatment: The patient was planned for endoscopic excision of the mass. A cystic lesion was seen filing the posterior aspect of the right nasal cavity. Lesion contained clear fluid (CSF). A bony defect about $5 \mathrm{mmx} 8 \mathrm{~mm}$ seen on the posterior fovea which was sealed with septal cartilage and bone. Post operative period was uneventful. Histopathology of mass showed mature glial elements, suggestive of nasal encephalocoele. 


\section{Discussion}

Encephalocele is defined as protrusion of cranial contents beyond the normal confines of the skull. They may contain meninges (meningocele), brain matter and meninges (meningoencephalocele) or they may communicate with the ventricles (meningoencephalocystocele). ${ }^{1}$ They can be grouped according to theiranatomical location into occipital, sincipital and basal.Encephaloceles can be congenital or acquired secondary to tumor, hydrocephalus or other cause. ${ }^{3}$ Nasal encephaloceles can be divided into frontoethmoidal and basal encephaloceles. Both conditions are very rare, but frontoethmoidal encephaloceles show a relatively high incidence $(1: 5,000)$ in Southeast Asia. The pathogenesis of encephaloceles may be explained by a disturbance in separation of surface ectoderm (epithelial layer) and neurectoderm (nervous tissue) in the midline just after closure of the neural folds. It should be regarded as a 'late' neurulation defect taking place during the 4th gestational week. ${ }^{4}$ Basal and frontoethmoidal encephaloceles constitute a nasal subclass of encephaloceles, which are herniations from the skull base and ethmoid bone, respectively. Basal encephaloceles are usually occult and can herniate into nasal structures causing obstruction. ${ }^{5}$

Differential diagnosis of this could be traumatic encephalocele, ethmoid-frontal sinus mucocele, neurinoma, hemangioma (the diagnosis becomes obvious if there is a clinical or palpable cerebral pulsation) and glioma.Computed tomography (CT) scans with appropriate bony and soft tissue brain windows and threedimensional reconstruction gives the best assessment. Thus, scans are integral to surgical planning. ${ }^{6}$ Indication of surgical repair of the lesion (anterior encephalocele) is usually cosmetic. Early surgical intervention is important, so that the deformity does not progress and to prevent infection if an encephalocele has ruptured. The goal is to return the cerebral components in to the cranial cavity along with amputation of dysplastic tissue and closure of the bony defect. ${ }^{6}$ Incomparison to children, fronto-nasal encephaloceles inadults, present a complicated situation for the surgeon,sinceadvancement in age enlarges the size of the defect, moregliotic brain tissue will be present in the herniation, alongwith an increase in size of the paranasal sinuses,thickcalvarial bones, large bony defect and sometimes scars fromprevious surgeries. ${ }^{7}$ Endoscopic excision of intranasal encephalocele is an effective method with high success rate as seen with our case. ${ }^{8}$

\section{References}

[1]. Suwanwela C. Geographical distribution of fronto-ethmoidal encephalomeningocele. Br J Prev Soc Med 1972; 26: 193-8

[2]. Barkovich AJ, et al. Congenital nasal masses: CT and MR imaging features in 16 cases. Am J Neuroradiol 1991; 12:105-16.

[3]. Holmes AD, Meara JG, Kolker AR, Rosenfeld JV, Klug GL. Frontoethmoidal encephaloceles: Reconstruction and refinements. J Craniofac Surg. 2001;12:6-18.

[4]. Hoving EW (2000) Nasal encephaloceles. Childs Nerv Syst 16:702-706

[5]. Tirumandas, M., Sharma, A., Gbenimacho, I. et al. Childs Nerv Syst (2013) 29: 739. doi:10.1007/s00381-012-1998-z

[6]. Mahapatra AK, Agrawal D. Anterior encephaloceles: A series of 103 cases. Journal Of Clinical Neuroscience.2006;13:536-9.

[7]. Agrawal A, Rao KS, Krishnamoorthy B, Shetty RB, Anand M, Jain H. Single stage craniofacial reconstruction for fronto-nasal encephalocele and hypertelorism in an adult. Singapore Med J 2007; 48: 215-9.

[8]. Abdel-Aziz M, El-Bosraty H, Qotb M, El-Hamamsy M, El-Sonbaty M, Abdel-Badie H, Zynabdeen M (2010) Nasal encephalocele: endoscopic excision with anesthetic consideration. Int J Pediatr Otorhinolaryngol 74:869-873. 